\begin{tabular}{|c|l|}
\hline Title & Production System for Biodegradable Polyester Poly hy droxy buty rate by Corynebacterium glutamicum \\
\hline Author(s) & Jo, Sung-Jin; Maeda, Michihisa; Ooi, Toshihiko; Taguchi, Seiichi \\
\hline Citation & $\begin{array}{l}\text { Journal of Bioscience and Bioengineering, 102(3), 233-236 } \\
\text { https://doi.org/10.1263jbb.102.233 }\end{array}$ \\
\hline Issue Date & 2006-09 \\
\hline Doc URL & http://hdl.handle.net/2115/16902 \\
\hline Type & article (author version) \\
\hline File Information & JB\&B102-3.pdf \\
\hline
\end{tabular}

Instructions for use 


\section{Production System for Biodegradable Polyester Polyhydroxybutyrate by Corynebacterium glutamicum}

\section{NOTES}

Sung-Jin Jo, ${ }^{1}$ Michihisa Maeda, ${ }^{2}$ Toshihiko Ooi, ${ }^{1}$ and Seiichi Taguchi ${ }^{1}{ }^{*}$

Division of Biotechnology and Macromolecular Chemistry, Graduate School of Engineering, Hokkaido University, N13W8, Kita-ku, Sapporo-shi, Hokkaido 060-8628, Japan $^{1}$ and School of Agriculture, Meiji University, 1-1-1, Higashimita, Tama-ku, Kawasaki-shi, Kanagawa 214-8571, Japan²

Received 9 May 2006 / Accepted 23 May 2006

* corresponding author. e-mail: staguchi@eng.hokudai.ac.jp

phone/fax: +81-(0)11-706-6610

[Key words: poly(3-hydroxybutyrate), Corynebacterium glutamicum, biodegradable plastic, biopolyester] 
A biosynthetic pathway for poly(3-hydroxybutyrate) [P(3HB)] production by Corynebacterium glutamicum was developed by introducing the phbCAB operon derived from Ralstonia eutropha. $\mathrm{P}(3 \mathrm{HB})$ synthase activity was detected in this recombinant C. glutamicum carrying a cell surface protein gene promoter. Intracellular $\mathrm{P}(3 \mathrm{HB})$ was microscopically observed as inclusion granules and its content was calculated to be $22.5 \%(\mathrm{w} / \mathrm{w})$ with a number average molecular weight of $2.1 \times 10^{5}$ and a polydispersity of 1.63 . 
Poly-3-hydroxybutyrate $[\mathrm{P}(3 \mathrm{HB})]$ is a biologically produced polyester that has received much attention as a biodegradable polymer and can be produced from biorenewable resources. $\mathrm{P}(3 \mathrm{HB})$ and its derivatives have many attractive properties. They can be used as bulk commodity plastics, in fishing lines, and medically, because of their biodegradability and biocompatibility. Despite the apparent benefits of using $\mathrm{P}(3 \mathrm{HB})$ as a replacement for petrochemical-derived plastics, the use and distribution of $\mathrm{P}(3 \mathrm{HB})$ have been limited by production cost. This problem is currently being addressed by engineering enzymes involved in $\mathrm{P}(3 \mathrm{HB})$ production $(1,2)$.

Although several genetic engineering approaches to improve $\mathrm{P}(3 \mathrm{HB})$ productivity have been reported, they have been used in only gram-negative bacteria including Escherichia coli, Ralstonia eutropha, and Pseudomonas strains (3). For the medical or food contact applications of $\mathrm{P}(3 \mathrm{HB})$, bacterial host selection for $\mathrm{P}(3 \mathrm{HB})$ production should be carefully considered, because gram-negative bacteria produce poisonous substances, i.e, endotoxins. The level of contaminated endotoxins from gram-negative bacteria can be reduced to some extent during $\mathrm{P}(3 \mathrm{HB})$ preparation by chloroform or $\mathrm{NaOH}$ treatment, but a trace amount of endotoxins still remain (4). To avoid such harmful contaminants, the use of gram-positive bacteria for $\mathrm{P}(3 \mathrm{HB})$ production is preferable. Gram-positive bacteria, particularly native $\mathrm{P}(3 \mathrm{HB})$-producing Bacillus strains, have long been studied for efficient $\mathrm{P}(3 \mathrm{HB})$ production but their productivities are extremely low (5). However, $\mathrm{P}(3 \mathrm{HB})$ production by recombinant gram-positive bacteria has rarely been reported.

Corynebacterium glutamicum is an aerobic, gram-positive, nonsporulating bacterium that has been extensively employed for the industrial production of several amino acids, based on classical metabolic engineering, that have been used in food, 
feed and pharmaceutical products for several decades $(6,7)$. The metabolic pathways and whole genome sequence of this bacterium have recently been reported (http://www.genome.ad.jp/kegg/pathway.html; 8). Hence, C. glutamicum is an attractive candidate host for $\mathrm{P}(3 \mathrm{HB})$ production at the genome-wide level. Acetyl-CoA generated from sugars via glycolysis is a key compound for the biosynthesis of various biomaterials such as amino acids and fatty acids. Acetyl-CoA is also a starting substance required for the $\mathrm{P}(3 \mathrm{HB})$ biosynthetic pathway consisting of 3 hydroxybutyryl-CoA (3HB-CoA) synthesis [catalyzed by $\beta$-ketothiolase (PhbA) and NADPH-dependent acetoacetyl-CoA reductase $(\mathrm{PhbB})]$ and the polymerization of 3HB-CoA to $\mathrm{P}(3 \mathrm{HB})$ [catalyzed by $\mathrm{P}(3 \mathrm{HB})$ synthase (PhbC)]. Figure $1 \mathrm{~A}$ shows the metabolic linkage between the glutamate synthetic pathway and our proposed $\mathrm{P}(3 \mathrm{HB})$ synthetic pathway. As a metabolic design, we tried to channel acetyl-CoA into an artificial $\mathrm{P}(3 \mathrm{HB})$ synthesis pathway. To this end, an artificial $\mathrm{P}(3 \mathrm{HB})$ synthetic pathway was developed in C. glutamicum by introducing an $R$. eutropha-derived phbCAB operon, as shown in Fig. 1B.

E. coli JM109 was used for genetic manipulation and grown at $37^{\circ} \mathrm{C}$ in LuriaBertani (LB) medium. When necessary, ampicillin (100 $\mu \mathrm{g} / \mathrm{ml})$ or kanamycin (50 $\mu \mathrm{g} / \mathrm{ml}$ ) was added to the medium. C. glutamicum ATCC13869, provided by Dr. K. Yokoyama of Ajinomoto Co. Inc., was used for transformation and $\mathrm{P}(3 \mathrm{HB})$ biosynthetic gene expression. C. glutamicum was transformed by electroporation as described previously (9). Three media were evaluated for the efficient production of $\mathrm{P}(3 \mathrm{HB})$ in C. glutamicum: LB medium, a nutrient-rich (CM2G, 10) medium and a minimal (MMTG, 10) medium often used for accelerating protein production in $C$. glutamicum. $\mathrm{P}(3 \mathrm{HB})$ production was observed only for MMTG medium. Thus, 
MMTG medium was used in the following experiments. Kanamycin was added to the medium at $50 \mu \mathrm{g} / \mathrm{ml}$. The C. glutamicum transformant was cultivated at $30^{\circ} \mathrm{C}$ for $72 \mathrm{~h}$. Cells harvested were by centrifugation at 14,000xg for 2 min and disrupted by sonication (4 sec, 15 times) on ice. Cell debris was precipitated by centrifugation at 14,000xg for 15 min to prepare whole cell extract. The $\mathrm{P}(3 \mathrm{HB})$ synthase (PhbC) activity of the whole cell extract was determined at $25^{\circ} \mathrm{C}$ by measuring the amount of released CoA during the polymerization of 3HB-CoA in absorbance at $412 \mathrm{~nm}$, as described previously (11).

The $\mathrm{P}(3 \mathrm{HB})$ content of the transformant was quantitated by high-performance liquid chromatography at $60^{\circ} \mathrm{C}$ using an Aminex HPX-87H ion exclusion column (7.8 mm I.D. x 300 mm; Bio-Rad Laboratories, Hercules, CA, USA). P(3HB) was converted to crotonic acid with concentrated sulfuric acid and diluted 10-fold with $0.014 \mathrm{~N} \mathrm{H}_{2} \mathrm{SO}_{4}$. Samples were filtered through a 0.45- $\mu \mathrm{m}$ PTFE membrane (Advantec, Tokyo) and eluted with $0.014 \mathrm{~N} \mathrm{H}_{2} \mathrm{SO}_{4}$ at a flow rate of $0.7 \mathrm{ml} / \mathrm{min}$. The absorbance of crotonic acid was measured at $210 \mathrm{~nm}$ (12). The molecular weight of $\mathrm{P}(3 \mathrm{HB})$ was determined by gel permeation chromatography (GPC) at $40^{\circ} \mathrm{C}$ using a Jasco GPC-900 system equipped with tandem columns of TSK gel GMH $\mathrm{HR}-\mathrm{M}$ (7.8 mm I.D. x 300 mm; Tosho, Tokyo) and Shodex XF-804L (8 mm I.D. x 300 mm; Showa Denko K. K., Tokyo). Chloroform was used as an eluent at a flow rate of $0.8 \mathrm{ml} / \mathrm{min}$, and calibration was performed using standard polystyrene samples. For transmission electron microscopy (TEM), C. glutamicum cells were fixed in 2\% glutaraldehyde in $100 \mathrm{mM}$ sodium cacodylate buffer ( $\mathrm{pH} 7.4$ ) for $1 \mathrm{~h}$ and postfixed in $2 \%$ osmium tetroxide for 30 min. The samples were dehydrated in a graded ethanol series and embedded in Epon812 epoxy resin. Ultrathin sections were prepared, poststained with uranyl acetate 
and lead acetate, and examined using an electron microscope (JEM-2010; Jeol, Tokyo).

To express the $\mathrm{P}(3 \mathrm{HB})$ biosynthesis genes from $R$. eutropha in C. glutamicum, two expression plasmids, pPGEM-phbCAB and pPS-phbCAB, were constructed, as shown in Fig. 1B. These two plasmids can be used in C. glutamicum and E. coli as shuttle vectors. An 5.0-kb SmaI-BamHI fragment containing the phb promoter, $\mathrm{P}(3 \mathrm{HB})$ biosynthesis (phbCAB) genes, and the phb terminator of $R$. eutropha from pGEM-phbCAB (13) was inserted into the KpnI-BamHI site of the pPSPTG1 vector (10) after being blunt-ended at the KpnI site. The resulting expression plasmid pPGEM-phbCAB was constructed so that the phbCAB genes could be expressed under the control of the phb promoter. An expression plasmid, pPS-phbCAB, was constructed using a 4.3-kb blunt-ended Csp45I-BamHI fragment of pGEM-phbCAB containing phbCAB and the phb terminator subcloned into the blunt-ended BstEIIBamHI site of pPSPTG1. The expression of the $p h b C A B$ operon was controlled by the promoter for the gene ( $\operatorname{csp} B$ ) encoding a cell surface protein $\mathrm{B}$; the $\operatorname{csp} B$ promoter has been used for the high production of the protein of interest in C. glutamicum (10). Both C. glutamicum transformants harboring pPGEM-phbCAB and pPS-phbCAB grew similarly in MMTG medium, but PhbC activity in the whole cell extracts was detected only in the pPS-phbCAB transformant (data not shown). These results indicate that the $R$. eutropha-derived phbCAB-specific promoter is not functional in $C$. glutamicum cells, whereas the $\operatorname{cspB}$ promoter can be operated in C. glutamicum for the expression of the phbCAB operon from $R$. eutropha. Monomer supplying enzyme genes, $p h b A$ and $p h b B$, are expected to be expressed in $C$. glutamicum by the formation of an operon with phbC.

The culture conditions of the $C$. glutamicum transformant with pPS-phbCAB 
for $\mathrm{P}(3 \mathrm{HB})$ production were investigated in terms of the initial $\mathrm{pH}$ of $\mathrm{MMTG}$ medium and cultivation temperature. Maximum cell growth after 72-h cultivation was observed at $27^{\circ} \mathrm{C}$ and $\mathrm{pH} 7.5$, whereas maximum $\mathrm{P}(3 \mathrm{HB})$ production was obtained at $30^{\circ} \mathrm{C}$ and $\mathrm{pH}$ 7.5. Therefore, cultivation for $\mathrm{P}(3 \mathrm{HB})$ production of was performed at $30^{\circ} \mathrm{C}$ and $\mathrm{pH}$ 7.5. The time courses of cell growth and $\mathrm{P}(3 \mathrm{HB})$ production were plotted to overlap with each other, as shown in Fig. 2. Essentially, a synchronized pattern was obtained between cell growth and $\mathrm{P}(3 \mathrm{HB})$ production during the course of cultivation. Cell growth reached $12.5 \mathrm{mg} / \mathrm{ml}$ at $36 \mathrm{~h}$, whereas $\mathrm{P}(3 \mathrm{HB})$ content linearly increased up to $48 \mathrm{~h}$ and plateaued at about 22.5\% (w/w), which continued until 96 h of cultivation. Gas chromatographic and nuclear magnetic resonance spectroscopic analyses based on previous procedures (14) revealed that the accumulated polymer in the recombinant $C$. glutamicum is a homopolymer consisting of only 3HB-monomer units (data not shown).

Intracellular $\mathrm{P}(3 \mathrm{HB})$ was observed as inclusion granules within C. glutamicum cells harboring pPS-phbCAB by TEM, as shown in Fig. 3. The shape and size of the fully grown cells which accumulated $\mathrm{P}(3 \mathrm{HB})$ granules were unchanged, contrary to the filamentous morphologenesis often observed in recombinant E. coli producing $\mathrm{P}(3 \mathrm{HB})(15)$

By GPC, the synthesized P(3HB) prepared from 72-h-cultivation cells showed a number average molecular weight $(\mathrm{Mn})$ and a polydispersity of $2.1 \times 10^{5}$ and 1.63 , respectively, which differed from those of $\mathrm{P}(3 \mathrm{HB})\left(\mathrm{Mn}\right.$ of $1.8 \times 10^{6}$ and polydispersity of 1.8) synthesized in the recombinant $E$. coli harboring the phbCAB operon from $R$. eutropha, as shown in Table 1. The differences in these properties between $\mathrm{P}(3 \mathrm{HB})$ s synthesized by both bacterial strains could be due to the differences 
between individual physiological features such as monomer supplying ability and the expression levels of $\mathrm{P}(3 \mathrm{HB})$ biosynthetic genes. Although the $\mathrm{P}(3 \mathrm{HB})$ content of the recombinant C. glutamicum was lower than that of the recombinant E. coli, the cell density of the recombinant C. glutamicum was almost 4-fold that of the recombinant E. coli (Table 1). These results indicate that $\mathrm{P}(3 \mathrm{HB})$ production by recombinant $C$. glutamicum is more efficient than that by recombinant E. coli. The $\mathrm{P}(3 \mathrm{HB})$ production system in C. glutamicum can be improved by analyzing the metabolic flux of acetyl-CoA or the polarity effect of the promoter used.

This is the first report on an endotoxin-free production system of $\mathrm{P}(3 \mathrm{HB})$ in recombinant C. glutamicum by constructing an artificial $\mathrm{P}(3 \mathrm{HB})$ biosynthetic pathway channeling acetyl-CoA. This beneficial system will facilitate further next-generation research studies such as those on the biosynthesis of 3HB-based copolymers with desirable properties and the industrial production of biopolymers together with amino acids from renewable carbon sources.

The patents including this study were submitted with entry numbers, 2006140882 (for Japan) and 11/471986 (for USA). Our work described here was partly supported by a Grant-in-Aid for Scientific Research of Japan (No. 70216828) from the Ministry of Education, Culture, Sports, Science, and Technology of Japan (to S. Taguchi) and the Industrial Technology Research Grant Program in 2003 from the New Energy and Industrial Technology Development Organization (NEDO). 


\section{REFERENCES}

1. Taguchi, S. and Doi, Y.: Evolution of polyhydroxyalkanoate (PHA) production system by "enzyme evolution": successful case studies of directed evolution. Macromol. Biosci., 4, 146-156 (2004).

2. Nomura, C.T. and Taguchi, S.: PHA synthase engineering towards super-catalysts for custom-made biopolymers. Appl. Microbiol. Biotechnol., (2006) (in press).

3. Taguchi, K., Taguchi, S., Sudesh, K., Maehara, A., Tsuge, T., and Doi, Y.: Metabolic pathways and engineering of PHA biosynthesis, In Biopolymers. Doi, Y. and Steinbüchel, A. eds., p. 217-247. Wiley-VCH, Weinheim (2001).

4. Lee, S.Y., Choi, J., Han, K., and Song, J.Y.: Removal of endotoxin during purification of poly (3-hydroxybutyrate) from gram-negative bacteria. Appl. Environ. Microbiol., 65, 2762-2764 (1999).

5. Wu, Q., Huang, H., Hu, G., Chen, J., Ho, K., and Chen, G.Q.: Production of poly-3-hydroxybutyrate by Bacillus sp. JMa5 cultivated in molasses media. Antonie van Leeuwenhoek, 80, 111-118 (2001).

6. Kinoshita, S., Udaka, S., and Shimono, M.: Studies on the amino acid fermentation part I. Production of L-glutamic acid by various microorganisms. J. Gen. Appl. Microbiol., 3, 193-205 (1957).

7. Leuchtenberger, W., Huthmacher, K., and Drauz, K.: Biotechnological production of amino acids and derivatives: current status and prospects. Appl. Microbiol. Biotechnol., 69, 1-8 (2005).

8. Kalinowski, J., Bathe, B., Bartels, D., Bischoff, N., Bott, M., Burkovski, A., Dusch, N., Eggeling, L., Eikmanns, J. B., and other 18 authors: The complete Corynebacterium glutamicum ATCC 13032 genome sequence and its impact on the 
production of L-aspartate-derived amino acids and vitamins. J. Biotechnol., 104, 525 (2003).

9. Liebl, W., Bayerl, A., Schein, B., Stillner, U., and Schleifer, K.H.: High efficiency electroporation of intact Corynebacterium glutamicum cells. FEMS Microbiol. Lett., 65, 299-303 (1989).

10. Kikuchi, Y., Date, M., Yokoyama, K., Umezawa, Y., and Matsui, H.: Secretion of active-form Streptoverticillium monaraense transglutaminase by Corynebacterium glutamicum: processing of the pro-transglutaminase by a cosecreted subtilisin-like protease from Streptomyces albogriseolus. Appl. Environ. Microbiol., 69, 358-366 (2003).

11. Satoh, Y., Tajima, K., Tannai, H., and Munekata, M.: Enzyme-catalyzed poly(3hydroxybutyrate) synthesis from acetate with CoA recycling and NADPH regeneration in vitro. J. Biosci. Bioeng., 95, 335-341 (2003).

12. Karr, D.B., Waters, J.K., and Emerich, D.W.: Analysis of poly- $\beta$ hydroxybutyrate in Rhisobium japonicum bacteroids by ion-exclusion high-pressure liquid chromatography and UV detection. Appl. Environ. Microbiol., 46, 1339-1344 (1983).

13. Taguchi, S., Maehara, A., Takase, K., Nakahara, M., Nakamura, H., and Doi, Y.: Analysis of mutational effects of a polyhydroxybutyrate (PHB) polymerase on bacterial PHB accumulation using an in vivo assay system. FEMS Microbiol. Lett., 198, 65-71 (2001).

14. Kato, M., Bao, H.J., Kang, C.K., Fukui, T., and Doi, Y.: Production of a novel copolyester of 3-hydroxybutyric acid and medium-chain-length 3-hydroxyalkanoic acids by Pseudomonas sp. 61-3 from sugars. Appl. Microbiol. Biotechnol., 45, 363- 
370 (1996).

15. Peters, V. and Rehm, B.H.A.: In vivo monitoring of PHA granule formation using GFP-labeled PHA synthases. FEMS Microbiol. Lett., 248, 93-100 (2005).

16. Agus, J., Kahar, P., Abe, H., Doi, Y., and Tsuge, T.: Molecular weight characterization of poly[(R)-3-hydroxybutyrate] synthesized by genetically engineered strains of Escherichia coli. Polym. Degrad. Stabil., 91, 1138-1146 (2006). 


\section{Figure legends}

FIG. 1. (A) Metabolic linkage between glutamate synthetic pathway and $\mathrm{P}(3 \mathrm{HB})$ synthetic pathway, and (B) structures of constructed plasmids pPGEM-phbCAB and pPS-phbCAB. Each plasmid carries a single operon (phbCAB) consisting of three genes, phbC ( $\mathrm{P}(3 \mathrm{HB})$ synthase), phbA ( $\beta$-ketothiolase), and phbB (NADPH-dependent acetoacetyl-CoA reductase) with the phb terminator. The expression of the operon was regulated by the $p h b$ promoter (Pphb) for pPGEM-phbCAB and the $\operatorname{cspB}$ promoter (Pcsp) for pPS-phbCAB. $\mathrm{Km}^{\mathrm{r}}$, Kanamycin resistance gene; ori, replication origin; $\mathrm{P}$, promoter; C, phbC; A, phbA; B, phbB; T, terminator.

FIG. 2. Time courses of cell growth (dry cell weight, DCW; closed circles) and P(3HB) content (open circles) during cultivation of recombinant C. glutamicum cells harboring pPS-phbCAB.

FIG. 3. TEM images of recombinant C. glutamicum cells harboring pPGEM-phbCAB (A) and pPS-phbCAB (B). $\mathrm{P}(3 \mathrm{HB})$ accumulation was observed as granules in the cytoplasm of the cell (B). Bars indicate $0.2 \mu \mathrm{m}$ (A) and $0.5 \mu \mathrm{m}$ (B), respectively. 
Table $1 \mathrm{P}(3 \mathrm{HB})$ biosynthesis of by C. glutamicum and E. coli recombinants

\begin{tabular}{|c|c|c|c|c|c|c|}
\hline Plasmid (strain) & $M \mathrm{w}$ & $M \mathrm{n}$ & $\begin{array}{c}\text { Polydispersity } \\
(M \mathrm{w} / M \mathrm{M})\end{array}$ & $\begin{array}{c}\text { Dry cell } \\
\text { weight } \\
(\mathrm{g} / \mathrm{l})\end{array}$ & $\begin{array}{c}\mathrm{P}(3 \mathrm{HB}) \\
\text { content } \\
(\%, \mathrm{w} / \mathrm{w})\end{array}$ & Ref. \\
\hline $\begin{array}{c}\text { pPS-phbCAB } \\
(\text { C. glutamicum })\end{array}$ & $3.4 \times 10^{5}$ & $2.1 \times 10^{5}$ & 1.63 & 12.5 & 22.5 & $\begin{array}{l}\text { This } \\
\text { study }\end{array}$ \\
\hline $\begin{array}{c}\text { pGEM-phbCAB } \\
(\text { E. coli })\end{array}$ & $3.2 \times 10^{6}$ & $1.8 \times 10^{6}$ & 1.8 & 3.2 & 33 & 16 \\
\hline
\end{tabular}




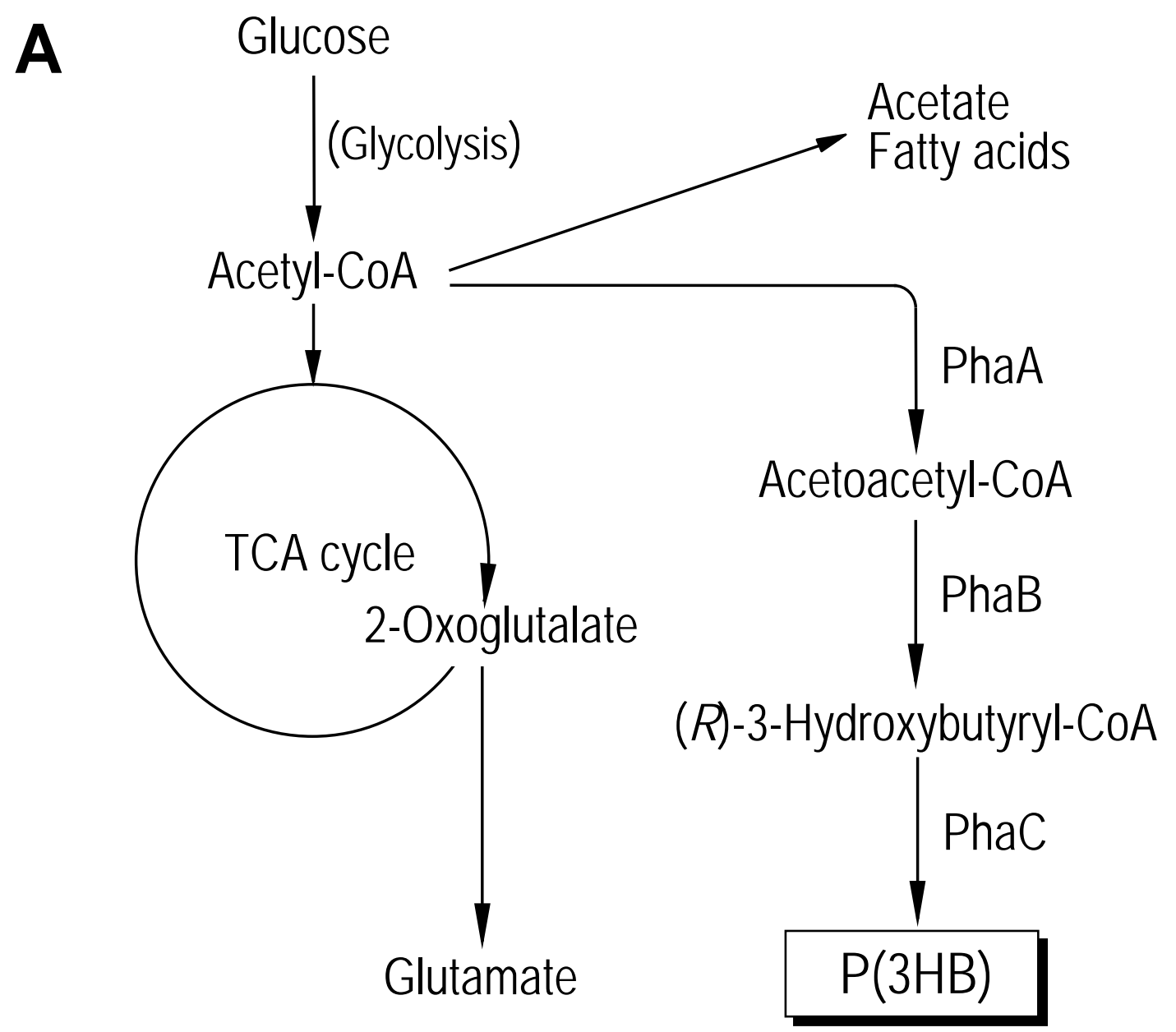

Fig. 1 (A). Jo SJ. et. al. 
B pPGEM-phbCAB $-P_{\text {phb }}$ phbC phbA phbB $T_{\text {phb }}$

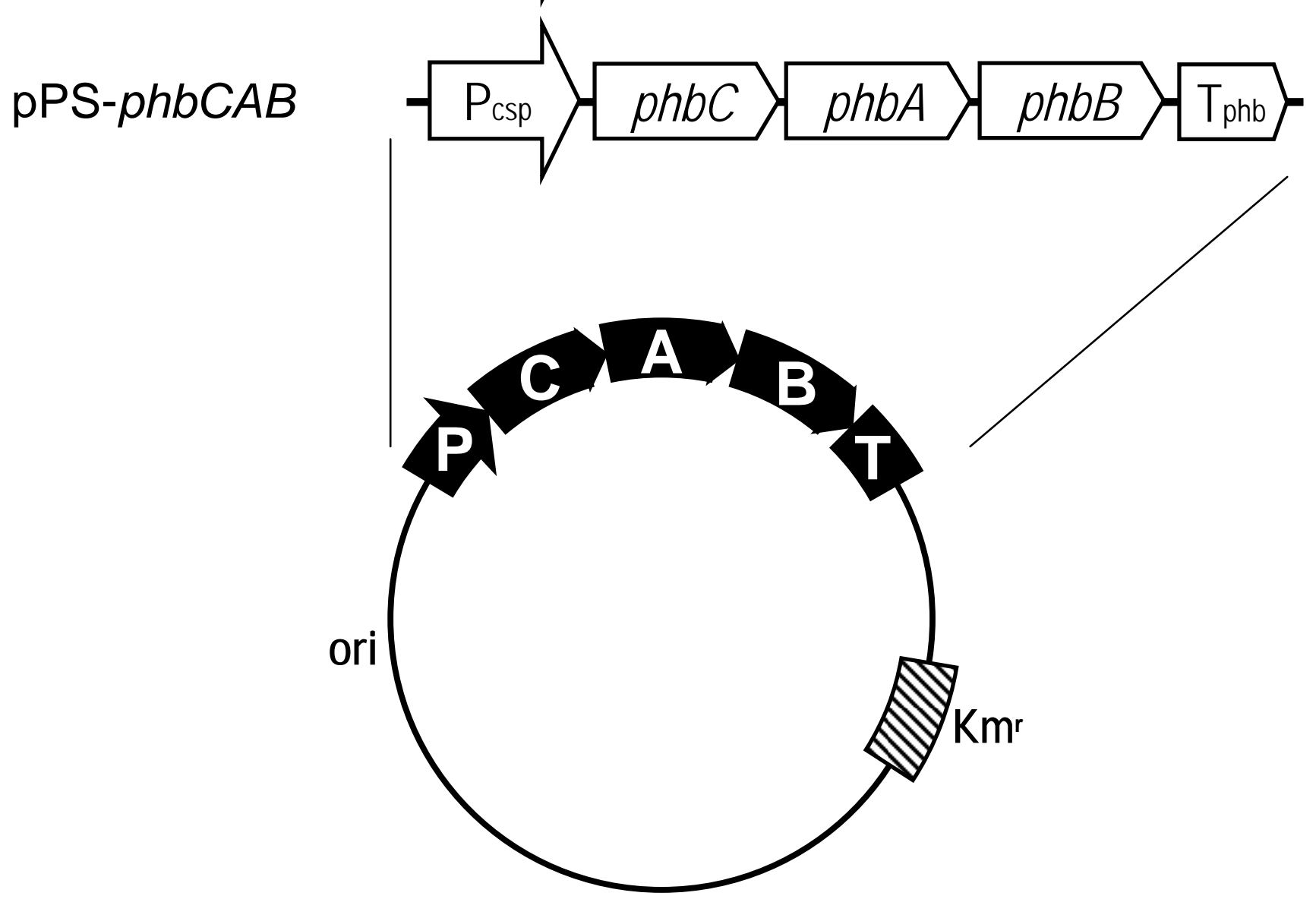

Fig. 1 (B). Jo SJ. et. al. 


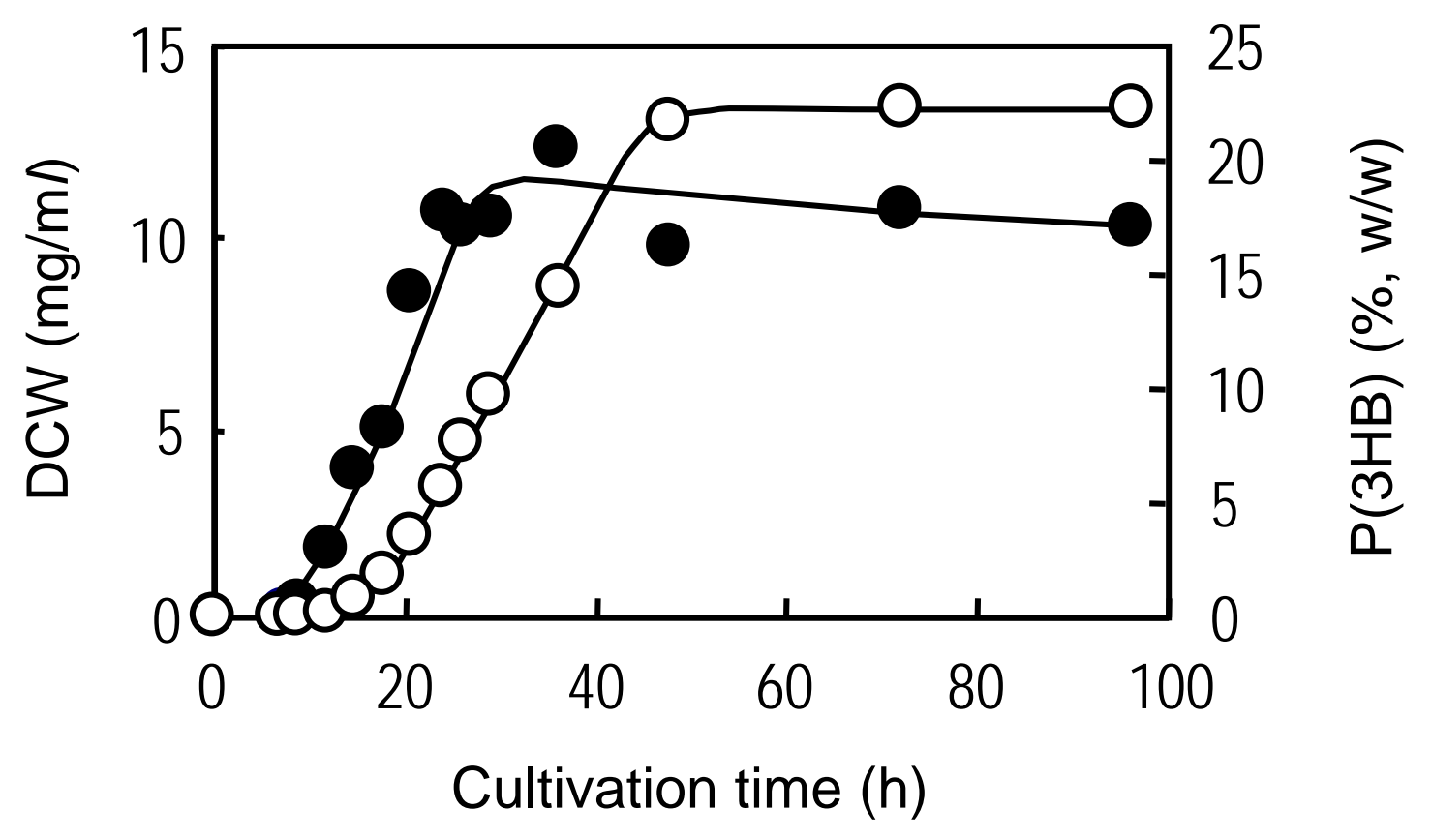

FIG. 2. Jo SJ. et. al. 


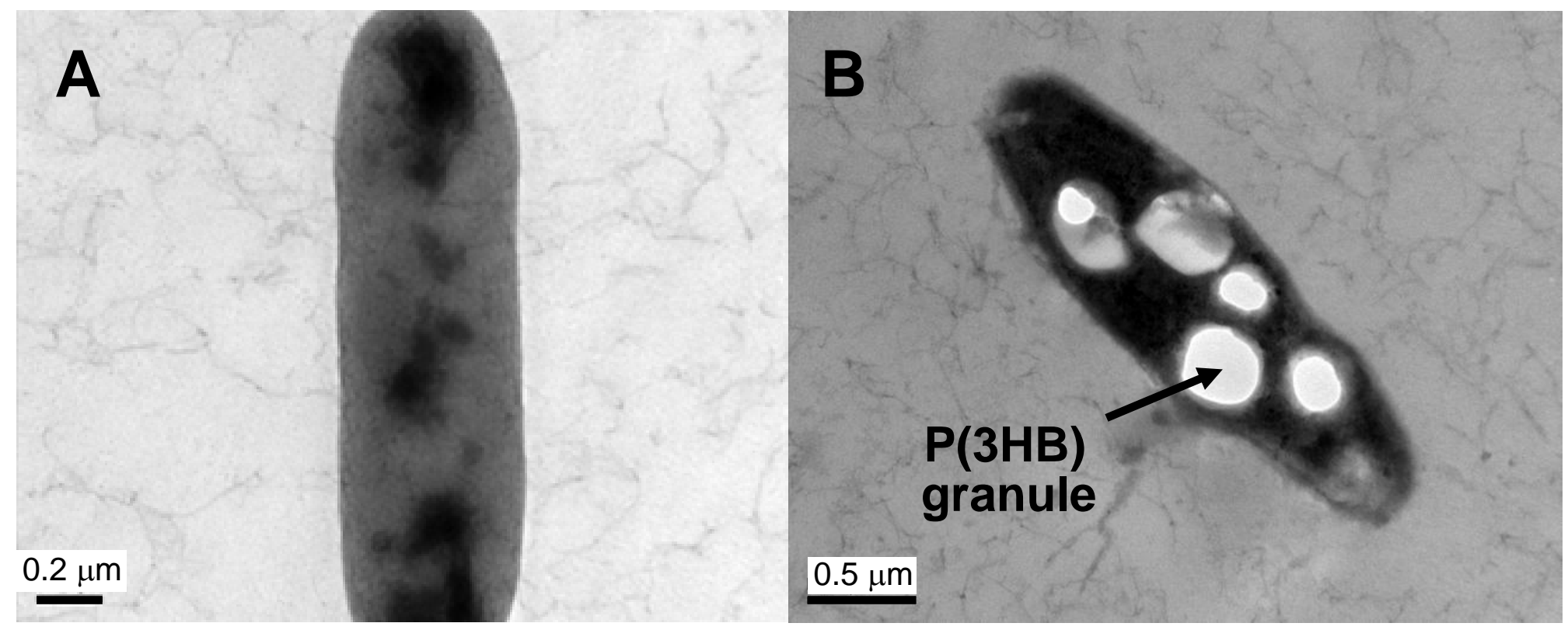

FIG. 3. Jo SJ. et. al. 